\title{
Salinomycin induces cell death via inactivation of Stat3 and downregulation of Skp2
}

\author{
KH Koo ${ }^{1}, \mathrm{H} \mathrm{Kim}^{1}$, Y-K Bae ${ }^{1}, \mathrm{~K} \mathrm{Kim}^{2}$, B-K Park ${ }^{3}$, C-H Lee ${ }^{*, 4}$ and Y-N Kim ${ }^{*, 1}$
}

Salinomycin has been shown to control breast cancer stem cells, although the mechanisms underlying its anticancer effects are not clear. Deregulation of cell cycle regulators play critical roles in tumorigenesis, and they have been considered as anticancer targets. In this study, we investigated salinomycin effect on cell cycle progression using OVCAR-8 ovarian cancer cell line and multidrug-resistant NCI/ADR-RES and DXR cell lines that are derived from OVCAR-8. Parental OVCAR-8 cells are sensitive to several anticancer drugs, but NCI/ADR-RES and DXR cells are resistant to several anticancer drugs. However, salinomycin caused cell growth inhibition and apoptosis via cell cycle arrest at G1 in all three cell lines. Salinomycin inhibited signal transducer and activator of transcription 3 (Stat3) activity and thus decreased expression of Stat3-target genes, including cyclin D1, Skp2, and survivin. Salinomycin induced degradation of Skp2 and thus accumulated p27Kip1. Knockdown of Skp2 further increased salinomycin-induced G1 arrest, but knockdown of p27Kip1 attenuated salinomycin effect on G1 arrest. Cdh1, an E3 ligase for Skp2, was shifted to nuclear fractions upon salinomycin treatment. Cdh1 knockdown by siRNA reversed salinomycin-

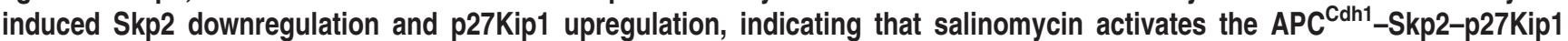
pathway. Concomitantly, si-Cdh1 inhibited salinomycin-induced G1 arrest. Taken together, our data indicate that salinomycin induces cell cycle arrest and apoptosis via downregulation or inactivation of cell cycle-associated oncogenes, such as Stat3, cyclin D1, and Skp2, regardless of multidrug resistance.

Cell Death and Disease (2013) 4, e693; doi:10.1038/cddis.2013.223; published online 27 June 2013

Subject Category: Cancer

Cancer cells can acquire multidrug resistance and/or apoptosis resistance to chemotherapy frequently by various mechanisms, which is a major problem in successful cancer treatment. ${ }^{1}$ It is thought that subsets within tumor populations acquire genetic alterations that confer drug resistance. Studies have suggested that subpopulations of cancer cells, namely cancer stem cells (CSCs), are responsible for cancer recurrence and drug resistance. ${ }^{2,3}$ CSCs possess tumor initiation, self-renewal capacity, invasion, metastasis, and therapeutic resistance. ${ }^{4}$ CSCs display numerous mechanisms of resistance to chemotherapeutic drugs, allowing them to survive current cancer therapies and initiate relapse. ${ }^{4,5}$ Therefore, in addition to killing the bulk of tumor cells, eradication of CSCs by molecular targeting of distinct deregulated signaling elements is required for complete cancer control. Recently, salinomycin has been identified as a highly effective chemical in the elimination of CSCs in a high-throughput screen. ${ }^{6}$
Salinomycin is a carboxylic polyether ionophore isolated from Streptomyces albus ${ }^{7}$ that has been widely used as an agricultural antibiotic to prevent coccidiosis in poultry. Salinomycin selectively kills CSCs in some types of cancer, such as breast cancer, leukemia, colorectal cancer, lung cancer, gastric cancer, and osteosarcoma. ${ }^{6,8-12}$ Salinomycin acts as a potent inhibitor of multidrug resistance protein 1 (MDR-1) (P-glycoprotein/ABCB1) and induces apoptosis in drug- and apoptosis-resistant human cancer cells. ${ }^{8,13,14}$ Salinomycin exerts its anticancer effects through the generation of ROS, and it also sensitizes anticancer drug- and radiationtreated cancer cells by increasing DNA damage. ${ }^{15-18}$ A recent study demonstrated that salinomycin inhibits Wnt signaling and selectively induces apoptosis in chronic lymphocytic leukemia cells. ${ }^{19}$ The ability of salinomycin to effectively kill both CSCs and apoptosis- or drug-resistant cancer cells may define the compound as a novel and effective anticancer agent. However, the biochemical basis and molecular

\footnotetext{
${ }^{1}$ Comparative Biomedicine Research Branch, Division of Cancer Biology, National Cancer Center, 323 Ilsan-ro, Ilsandong-gu, Goyang-si, Gyeonggi-do 410-769, Republic of Korea; ${ }^{2}$ Carcinogenesis Research Branch, Division of Cancer Epidemiology and Prevention, National Cancer Center, 323 Ilsan-ro, Ilsandong-gu, Goyang-si, Gyeonggi-do 410-769, Republic of Korea; ${ }^{3}$ Center for Pediatric Oncology, National Cancer Center, 323 Ilsan-ro, Ilsandong-gu, Goyang-si, Gyeonggi-do 410-769, Republic of Korea and ${ }^{4}$ Cancer Cell and Molecular Biology Branch, Division of Cancer Biology, National Cancer Center, 323 Ilsan-ro, Ilsandong-gu, Goyang-si, Gyeonggi-do 410-769, Republic of Korea

*Corresponding author: C-H Lee, Cancer Cell and Molecular Biology Branch, Division of Cancer Biology, National Cancer Center, 323 llsan-ro, llsandong-gu, Goyang-si, Gyeonggi-do 410-769, Republic of Korea. Tel: +82 31920 2201; Fax: +82 31920 2006; E-mail:chlee@ncc.re.kr

or Y-N Kim, Comparative Biomedicine Research Branch, Division of Cancer Biology, National Cancer Center, 323 Ilsan-ro, Ilsandong-gu, Goyang-si, Gyeonggi-do 410-769, Republic of Korea. Tel: +82 31920 2415; Fax: +82 31920 2468; E-mail: ynk@ncc.re.kr

Keywords: salinomycin; Stat3; Skp2; multidrug resistance; cancer stem cells

Abbreviations: SM, salinomycin; Stat3, signal transducer and activator of transcription 3; CSCs, cancer stem cells; Skp2, S-phase kinase-associated protein 2; siRNA, small interfering RNA; CDK, cyclin-dependent kinase; MDR-1, multidrug resistance protein 1; ABCB1, ATP-binding cassette subfamily B member 1; SCF, Skp, cullin, F-box containing; APC, anaphase-promoting complex

Received 22.1.13; revised 10.5.13; accepted 17.5.13; Edited by Y Shi
} 
mechanisms of the anticancer effects of salinomycin remain unclear.

The mammalian cell cycle is controlled by a subfamily of cyclin-dependent kinases (CDKs), the activity of which is modulated by several activators (cyclins) and inhibitors. ${ }^{20,21}$ Levels of cyclins and CDK inhibitors are regulated at both the transcriptional and post-translational levels. The Skp, cullin, and F-box-containing (SCF) complex and the anaphasepromoting complex (APC) are two major E3 ubiquitin ligases that govern levels of cyclins and CDK inhibitors at each cycle. $^{22}$ The G1- to S-phase transition is critical for cell cycle progression, and cyclin D1, a positive regulator of this transition, is a biomarker of cancer phenotype and disease progression. ${ }^{23-25}$ CDK inhibitors, such as p21Cip1 and p27Kip1, inhibit cell cycle progression, and low levels of p27Kip1 are associated with a poor prognosis in most cancers. $^{20,26}$ p27Kip1 is mainly regulated at the protein stability level, and its proteasomal degradation is preceded by ubiquitination mediated by S-phase kinase-associated protein 2 (Skp2), a critical component of the SCF E3 ligase complex. Skp2 is an oncogenic protein and is frequently overexpressed in many human tumors. Skp2 targets tumor suppressor proteins for degradation, especially p27Kip $1 .{ }^{27-29}$ Increased levels of Skp2 and decreased levels of p27Kip1 are observed in many types of cancer, and Skp2 has been associated with poor prognosis as well as tumor metastasis. ${ }^{27,30-32}$ Skp2 is known to be degraded via the APC ${ }^{\text {Cdh1 }}$ pathway. $^{33}$ Skp2 expression has also been associated with apoptosis resistance induced by TRAIL, radiation, and rapamycin. ${ }^{34-36}$ Therefore, Skp2 has been suggested as a novel and promising therapeutic target for cancer control.

In this study, we demonstrated that salinomycin induces cell growth inhibition and apoptosis via cell cycle arrest at G1 phase regardless of MDR-1 expression. We illustrated that the antitumor effects of salinomycin are due to its ability to inhibit the signal transducer and activator of transcription 3 (Stat3)-cyclin D1 pathway, degrade the Skp2 oncoprotein, and induce the accumulation of the p27Kip1 tumor suppressor.

\section{Results}

Multidrug resistance and MDR-1 expression in NCI/ADRRES and DXR cells. NCI/ADR-RES cells are multidrugresistant cells derived from OVCAR-8 human ovarian adenocarcinoma cells. ${ }^{37}$ We further established DXR cells by exposing NCI/ADR-RES cells to progressively higher concentrations of doxorubicin, which are able to survive up to $50 \mu \mathrm{M}$ doxorubicin. As expected, both NCI/ADR-RES and DXR cells are resistant to doxorubicin-induced cell death, whereas OVCAR-8 cells are sensitive. Compared with NCl/ADR-RES cells, DXR cells appeared to be more resistant to doxorubicin (Figure 1a). We further examined whether these doxorubicin-resistant cells obtained the multidrug resistance to various anticancer drugs (Figures $1 b-d$ ). $\mathrm{NCl} / \mathrm{ADR}-\mathrm{RES}$ and DXR cells exhibited resistance to paclitaxel, etoposide, and cisplatin compared with the parental OVCAR-8 cells. Next, we evaluated level of MDR-1, which is one of the major $A B C$ transporters associated with multidrug resistance. ${ }^{38}$ Levels of both mRNA and protein of MDR-1 were significantly increased in $\mathrm{NCl} / \mathrm{ADR}-\mathrm{RES}$ and DXR cells, whereas its expression was not detectable in OVCAR-8 cells (Figures 1e and f). Higher levels of MDR-1 expression were detected in DXR cells than in NCI/ADR-RES cells. Consistent with MDR-1 levels, low levels of accumulation of rhodamine123 or doxorubicin were observed in NCl/ADR-RES and DXR cells (Figure 1g). In addition, DXR cells contained lower levels of rhodamine123 or doxorubicin than NCl/ADR-RES cells. These data suggest that expression levels of MDR-1 are correlated with drug resistance and efflux of its substrates.

Salinomycin induces cell cycle arrest at G1 phase and apoptosis in the multidrug-resistant cells. To evaluate the effect of salinomycin on cell proliferation and survival, OVCAR-8, NCl/ADR-RES, and DXR cells were treated with different doses of salinomycin, and cell growth was measured by MTS assay and cell counting. Salinomycin treatment induced growth inhibition dose-dependently in all three cell lines regardless of MDR-1 expression (Figures 2a and b). DXR cells appeared to be a little more sensitive to salinomycin. To test whether this growth inhibition is due to cell death, we stained cells with annexin $\mathrm{V}$ and propidium iodide (PI) and found that apoptosis is increased with salinomycin treatment (Figure 2c). In addition, clonogenicity of both OVCAR-8 and DXR cells was reduced by salinomycin treatment as assessed by colony-forming assay (Figure $2 \mathrm{~d}$ ). Salinomycin activated apoptosis signaling, including decreases in phospho-Akt and phospho-Bad and increases in caspase-3 activation and PARP cleavage (Figure 2e). Some survival proteins, such as survivin and livin, decreased without changes in the levels of antiapoptotic proteins, including c-IAP1, c-IAP2, XIAP, and Bcl-xL, and a proapoptotic protein, Bax (Figure 2e). Because the cell growth rate was also decreased in the salinomycin-treated cells (Figure 2f), we tested whether the antiproliferative effect of salinomycin is associated with cell cycle arrest. Salinomycin caused accumulation of G1-phase cells and a slight decrease in $\mathrm{S}$-phase cells in all three cell lines (Figure $2 \mathrm{~g}$ ). There was a little increase in the sub-G1 population upon salinomycin treatment. This increase in the G1 cell population was mostly at the expense of G2/M cells. These results clearly suggest that salinomycin exerts its antiproliferative effect by inducing cell cycle arrest at G1 phase and, consequently, apoptosis.

Salinomycin treatment downregulates cyclin D1 and Skp2 and accumulates p27Kip1. Next, we determined the specific cell cycle regulators responsible for the cell cycle arrest induced by salinomycin by immunoblot analysis using antibodies specific to CDKs, cyclins, and CDK inhibitors. Salinomycin treatment markedly decreased protein levels of Skp2, cyclin D1, and cyclin A but did not change protein levels of CDK1 (Figure 3a). Salinomycin had little effect on the levels of CDK4 and CDK6, if any. The Skp2-containing SCF ubiquitin ligase (SCF ${ }^{\text {Skp2 }}$ ) targets cell cycle-negative regulators p27Kip1, p21Cip1, and p130Cas for proteasomal degradation and thereby controls progression through the cell cycle. ${ }^{29}$ Consistent with Skp2 reduction, salinomycin caused p27Kip1 accumulation in all three cell lines. Levels of another CDK inhibitor, p21Cip1, were slightly elevated upon 

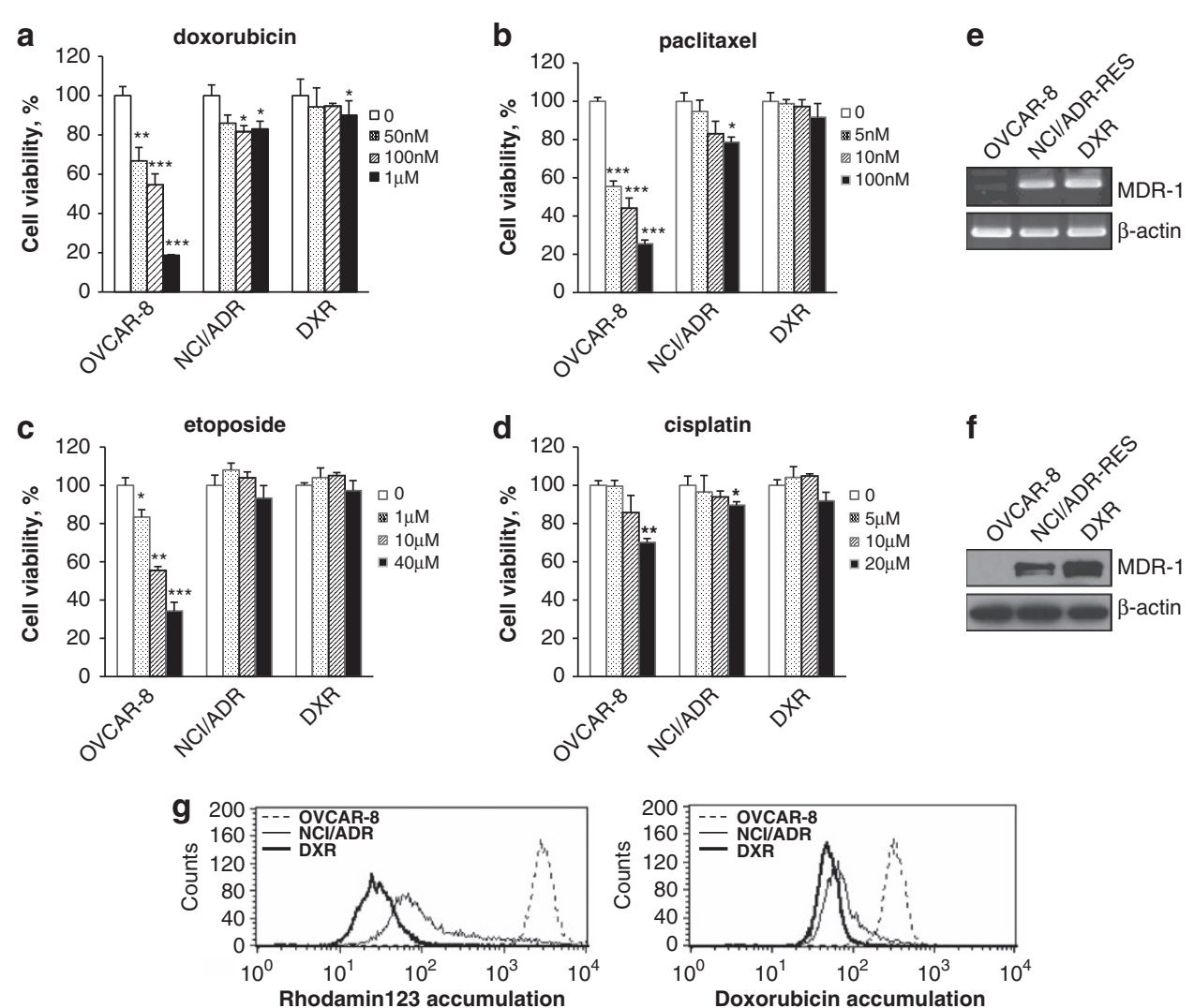

Figure 1 Multidrug resistance and MDR-1 expression in ovarian cancer cell lines, including OVCAR-8, NCI/ADR-RES, and DXR cells. OVCAR-8, NCI/ADR-RES, and DXR cells were treated with the indicated concentrations of (a) doxorubicin, (b) paclitaxel, (c) etoposide, and (d) cisplatin for $72 \mathrm{~h}$, and cell viability was determined by MTS assay. Data are presented as averages of triplicate measurements, with error bars representing standard deviations. ${ }^{\star} P<0.05,{ }^{* \star} P<0.005$, and ${ }^{* \star *} P<0.0005$. (e) The levels of MDR-1 mRNA were determined by RT-PCR in each cell line. (f) Equal amounts of cell lysates were subjected to immunoblot analysis using MDR-1 antibody. $\beta$-Actin was used as a loading control. (g) Cells were incubated with $10 \mu \mathrm{M}$ rhodamine 123 or $50 \mu \mathrm{M}$ doxorubicin for $2 \mathrm{~h}$, and the accumulation of rhodamine123 (left panel) and doxorubicin (right panel) was measured by flow cytometric analysis. These experiments were performed twice on separate samples with comparable results

salinomycin treatment, whereas the other CDK inhibitors p16INK4A and p15INK4B were not largely changed. Salinomycin did not change the expression of tumor suppressor genes, such as p53, PTEN, and p130Cas (Supplementary Figure 1). Because p27Kip1 acts as a decisive negative regulator of the cell cycle, p27Kip1 degradation is a critical event for the G1/S transition and occurs through ubiquitination by Skp2 and subsequent degradation by the $26 S$ proteasome. These results indicate that salinomycin downregulates cyclin D1 and Skp2 and induces p27Kip1 accumulation, leading to cell cycle arrest in the G1 phase.

To investigate how cyclin D1 and Skp2 are downregulated in salinomycin-treated cells, we examined mRNA levels by quantitative PCR (qPCR). The mRNA levels of cyclin D1 and Skp2 were decreased by $49 \%$ and $43 \%$ compared with those in the control, respectively (Figure $3 b$ ). Next, we examined the half-life of these proteins using cycloheximide ( $\mathrm{CHX})$, a protein synthesis inhibitor. Salinomycin did not alter cyclin D1 stability but decreased Skp2 stability approximately twofold (Figures $3 c$ and $d$ ). To further investigate whether salinomycin increases proteasomal degradation of cyclin D1 and Skp2, we evaluated those protein levels after salinomycin treatment in the presence or absence of MG132, a proteasome inhibitor (Figure 3e). MG132 could block salinomycin-induced Skp2 downregulation but not cyclin D1 downregulation. In addition, salinomycin treatment increased ubiquitination of Skp2 immunoprecipitates, indicating that salinomycin treatment decreases Skp2 via the proteasomal pathway (Figure 3f).

Salinomycin inhibits phosphorylation and transcriptional activity of Stat3. Stat3 is activated in ovarian cancers, and Stat3 activation is known to increase cyclin D1 and Skp2. ${ }^{39-41}$ Stat3 phosphorylation was significantly reduced by salinomycin in a dose-dependent manner without changes in total levels of Stat3 (Figure 4a). To analyze Stat3 activity changes, DXR cells were transfected with a Stat3-dependent luciferase reporter construct, 3xLy6E/ pZluc-TK, and treated with salinomycin. Stat3-dependent luciferase activities were also decreased by salinomycin treatment, which is comparable with the effects of a Stat3-specific inhibitor, S3I-201 (Figure 4b). S3I-201 reduced viability of DXR cells dose- and time-dependently (Figure 4c). S3I-201 treatment also caused a dose-dependent reduction of protein levels of Skp2, cyclin D1, and survivin and a concomitant rise in p27Kip1 expression (Figure 4d). To test whether Stat3 activation could reverse salinomycin effects, 


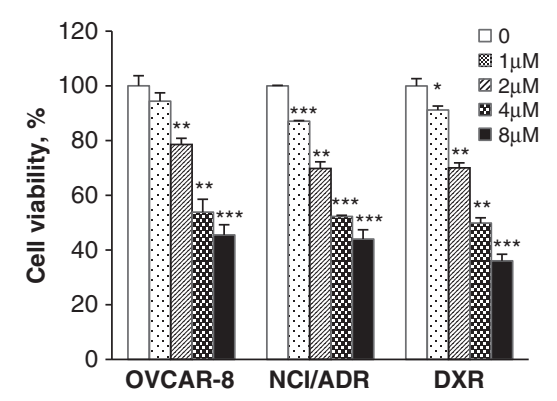

C

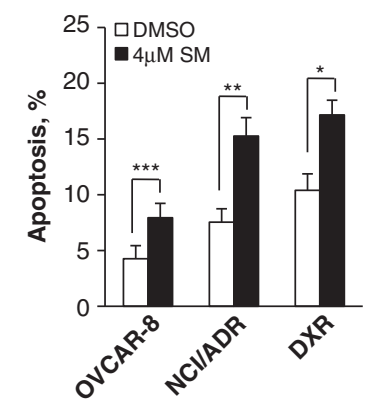

b

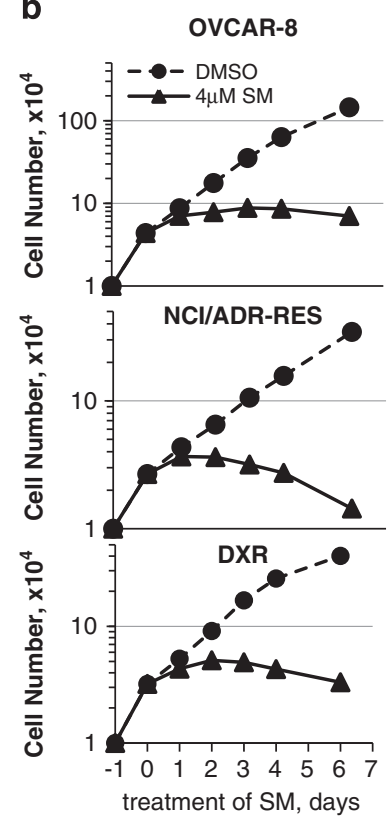

e

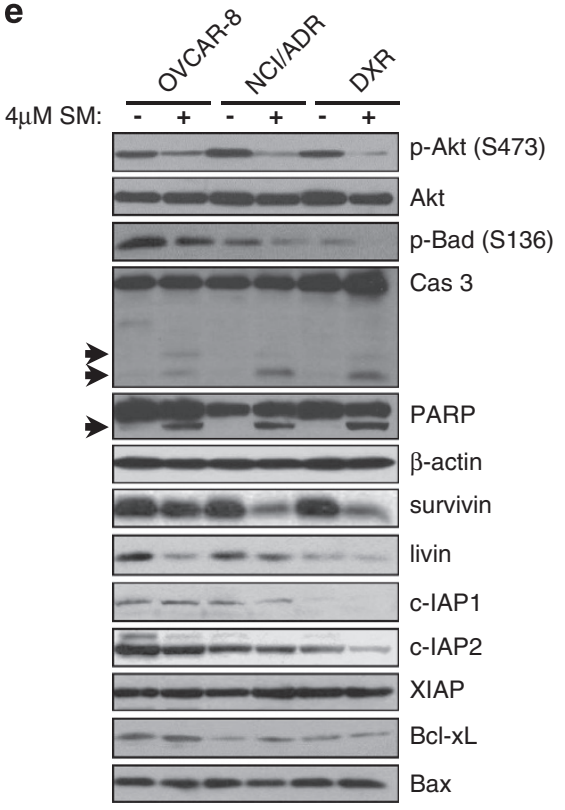

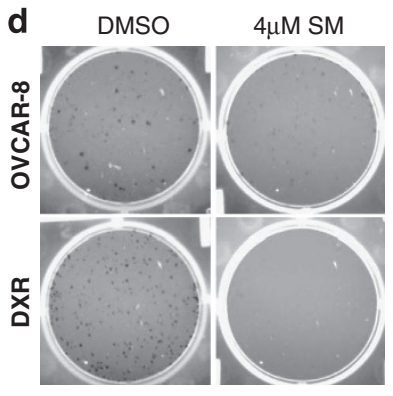

f

DMSO

$4 \mu \mathrm{M} \mathrm{SM}$

$8 \mu \mathrm{M} \mathrm{SM}$
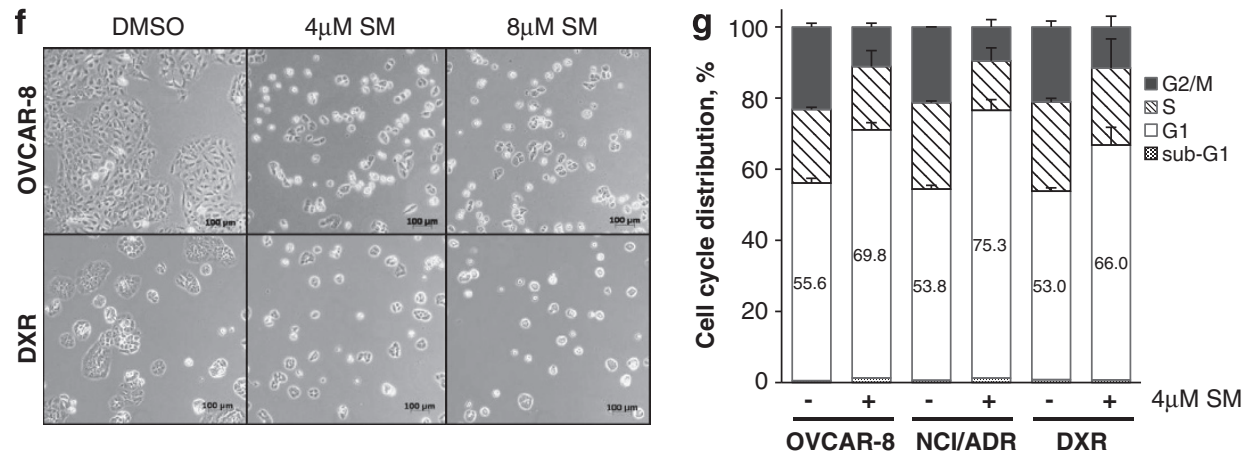

Figure 2 Salinomycin inhibits cell growth and induces apoptosis through cell cycle arrest at G1 phase. (a) Cells were treated with indicated concentrations of salinomycin for $72 \mathrm{~h}$, and cell growth inhibition was determined by MTS assay. Data are presented as averages of triplicate measurements, with error bars representing standard deviations. ${ }^{*} P<0.05,{ }^{* *} P<0.005$, and ${ }^{* *} P<0.0005$. (b) Cells were treated with $4 \mu \mathrm{M}$ salinomycin or DMSO vehicle, and cell numbers were counted using a cell counter at the indicated time points. (c) Cells were treated without or with $4 \mu \mathrm{M}$ salinomycin for $72 \mathrm{~h}$, and then apoptosis was measured by flow cytometric analysis of cells stained with annexin V and PI. The percentages of annexin V- or/and PI-positive cells are indicated. Data are presented as averages of triplicate measurements, with error bars representing standard deviations. ${ }^{*} P<0.05,{ }^{* *} P<0.005$, and ${ }^{* *} P<0.0005$. (d) Cells were treated without or with $4 \mu \mathrm{M}$ salinomycin for $72 \mathrm{~h}$. Cells were then replated and incubated in drug-free media for 10 days to allow colony formation. Colonies were stained with crystal violet. (e) Cells were treated without or with $4 \mu \mathrm{M}$ salinomycin for $72 \mathrm{~h}$, and then equal amounts of cell lysates were subjected to immunoblot analysis using the indicated antibodies. Similar results were observed in independent experiments. Arrows indicate cleaved forms of each protein. (f) Cells were treated without or with 4 and $8 \mu \mathrm{M}$ salinomycin for $24 \mathrm{~h}$, and images were taken using phase contrast microscopy. Magnification: $\times 50$; scale bar $=100 \mu \mathrm{m}$. (g) Cells were treated without or with $4 \mu \mathrm{M}$ salinomycin for $24 \mathrm{~h}$, and then cell cycle was analyzed by flow cytometry. The percentage of cells in G1 phase is annotated in each column. Similar results were observed in three independent experiments

we established the stable cell lines expressing the constitutively active Stat3 (CA-Stat3) (Figure 4e). When CA-Stat3 was overexpressed, both Skp2 downregulation and p27Kip1 upregulation were attenuated in response to salinomycin, indicating that Stat 3 activity could reverse the effects of salinomycin partially (Figure $4 \mathrm{f}$ and Supplementary Figure 2). Although cyclin D1 is an important target gene of Stat $3,{ }^{40}$ salinomycin-induced cyclin D1 downregulation was not recovered by CA-Stat3 expression. Because Stat3 is known to be activated through growth factor receptor pathways and cytokine receptor-Janus kinase (JAK) pathways, ${ }^{42}$ we tested whether salinomycin decreases activities of EGFR and JAK2. However, salinomycin did not affect activation of
EGFR and JAK2 as assessed by their phosphorylation (Supplementary Figure 3).

Expression levels of Skp2 and p27Kip1 are associated with sensitivity to salinomycin. To evaluate the roles of Skp2 and p27Kip1 in salinomycin-induced G1 arrest, expression of these two proteins was knocked down using small interfering RNAs (siRNAs) specific for either Skp2 or p27Kip1. Transfection with si-Skp2 efficiently reduced Skp2 levels and simultaneously increased p27Kip1 levels. Skp2 levels were abolished and p27Kip1 levels were much higher in the cells treated with salinomycin and si-Skp2 together. Transfection with si-p27Kip1 abolished both basal levels of 


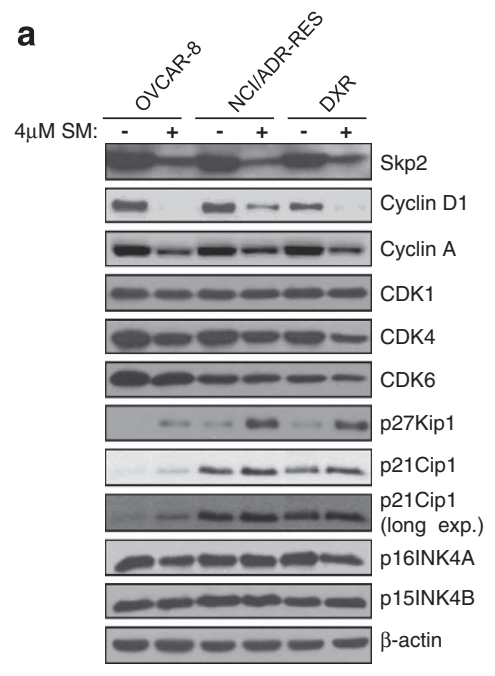

d

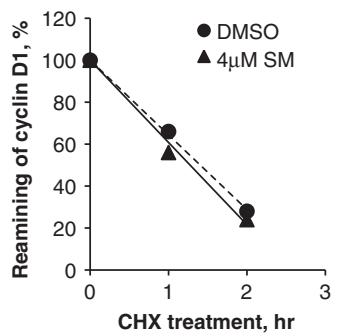

b

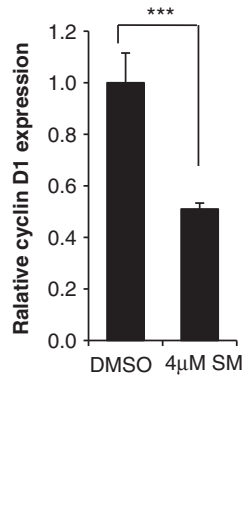

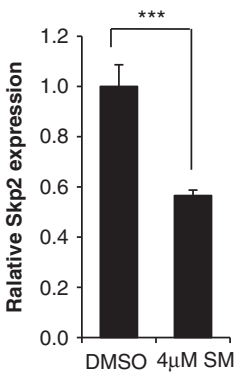

e

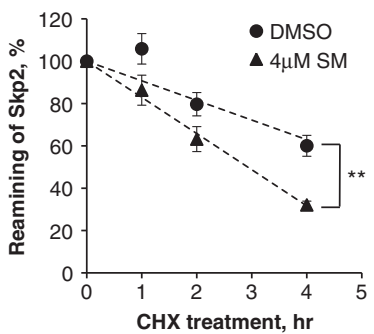

C
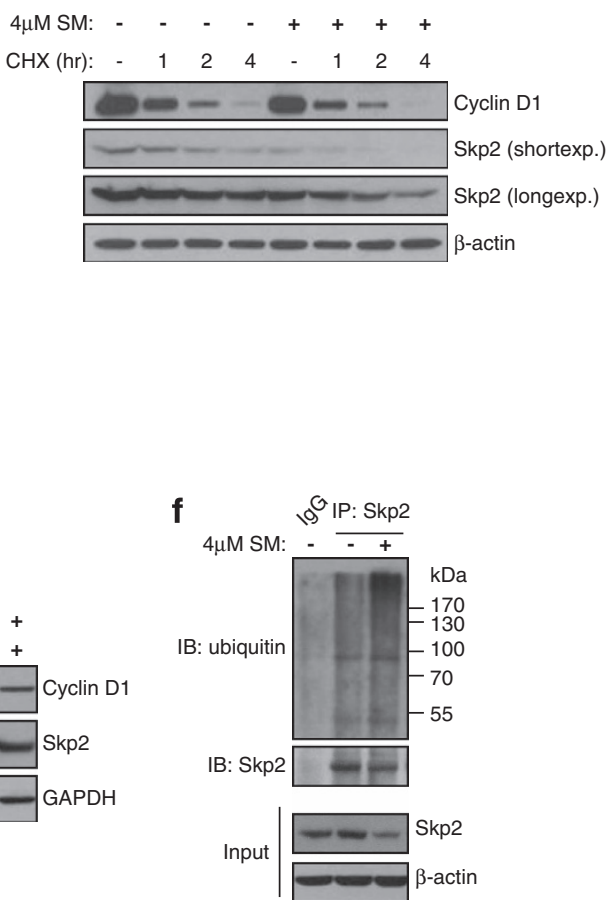

Figure 3 Salinomycin downregulates cyclin D1 and Skp2 and accumulates p27Kip1. (a) Cells were treated without or with $4 \mu \mathrm{M}$ salinomycin for $24 \mathrm{~h}$, and equal amounts of cell lysates were subjected to immunoblot analysis using the indicated antibodies. exp., exposure. (b) DXR cells were treated without or with $4 \mu \mathrm{M}$ salinomycin for $24 \mathrm{~h}$, and the levels of cyclin D1 and Skp2 mRNA were determined by qPCR. ${ }^{* * *} \mathrm{P}<0.0005$. (c) DXR cells were treated without or with $4 \mu \mathrm{M}$ salinomycin for $24 \mathrm{~h}$, and $10 \mu \mathrm{M} \mathrm{CHX}$ was added for the last 1, 2, and $4 \mathrm{~h}$ before harvest, followed by immunoblot analysis using cyclin D1 and Skp2 antibodies. exp., exposure. (d) The graph shows the quantitation of immunoblot analysis data shown in panel $c$. Data are presented as averages of triplicate experiments, with error bars representing standard deviations. ${ }^{*} P<0.005$. (e) $D X R$ cells were treated without or with $4 \mu \mathrm{M}$ salinomycin in the presence or absence of $10 \mu \mathrm{M}$ MG132 for $18 \mathrm{~h}$, and equal amounts of cell lysates were subjected to immunoblot analysis using cyclin D1 and Skp2 antibodies. GAPDH was used as a loading control. (f) DXR cells were treated without or with $4 \mu \mathrm{M}$ salinomycin for $18 \mathrm{~h}$, and cell lysates were subjected to immunoprecipitation using anti-Skp2 or normal rabbit lgG antibodies, followed by immunoblot analysis for ubiquitin and Skp2. Similar results were observed in independent experiments

p27Kip1 and salinomycin-induced p27Kip1 (Figure 5a). Consistent with these data, salinomycin-induced G1 arrest was enhanced by si-Skp2 but was significantly blocked by si-p27Kip1 (Figure 5b).

To test whether Skp2 expression levels correlate with the effect of salinomycin on cell growth inhibition, we employed the breast cancer cell lines MCF-7, SK-BR-3, and MDA-MB-468, which express different levels of Skp2 (Figure 5c). MCF-7 cells express lower levels of Skp2, and salinomycin treatment abolished Skp2 protein in these cells. Thus, they are most sensitive to salinomycin-induced cell growth inhibition (Figure $5 \mathrm{~d}$ ). In contrast, salinomycin-induced cell growth inhibition was slower in the MDA-MB-468 cells, which express the highest Skp2 protein level of the three cell lines (Figure 5d). Salinomycin treatment also decreased Skp2 levels and induced cell growth inhibition in the A549 cells (Figure 5e). These results suggest that salinomycin induced Skp2 downregulation, which allows the p27Kip1 accumulation that is critical for $\mathrm{G} 1$ arrest and cell growth inhibition.

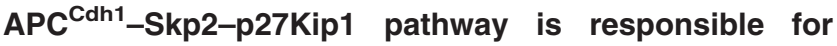
salinomycin-induced $\mathbf{G 1}$ arrest. The stability of Skp2 protein is regulated by multiple pathways, including phosphorylation and proteasomal degradation. Phosphorylation of Skp2 by Pim-1, Akt1, and CDK2 on Ser ${ }^{64}$ and $\mathrm{Ser}^{72}$ protects it from degradation by the APC ${ }^{\text {Cdh1 }} .^{43-45}$ Recently, Skp2 was shown to be destabilized by von Hippel-Lindau protein ( $p V H L)$ upon DNA damage. ${ }^{46}$ Therefore, we examined whether salinomycin treatment alters the levels of Skp2-regulating proteins. The levels of Pim-1, Cdh1, and pVHL were not changed, whereas the levels of CDK2 were decreased by salinomycin (Figure 6a). Although the levels of protein and mRNA of Cdh1 were not changed (Figures $6 \mathrm{a}$ and b), Cdh1 levels in the nuclear fraction were increased and Skp2 levels were decreased in both the cytosolic and nuclear fractions by salinomycin (Figure 6c), indicating that Skp2 is degraded by the APC/Cdh1 complex. To further investigate this possibility, we knocked down Cdh1 expression using si-Cdh1. Cdh1 downregulation accumulated Skp2 levels and maintained Skp2 levels even in the salinomycin-treated cells (Figure 6d). Consistent with the increased Skp2 levels, salinomycin treatment did not upregulate p27Kip1 levels in the cells transfected with si-Cdh1 when compared with cells transfected with siRNAs 


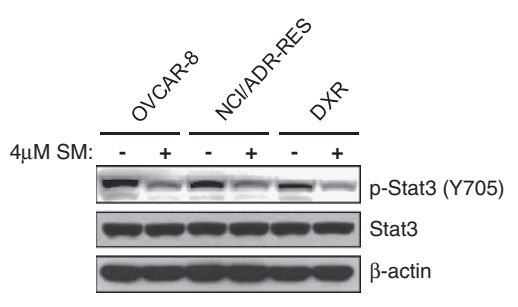

d

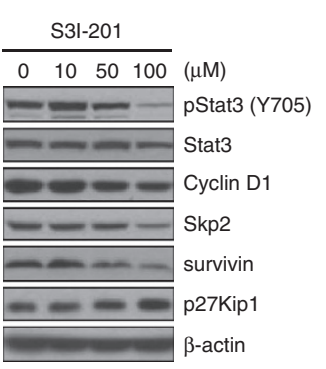

e

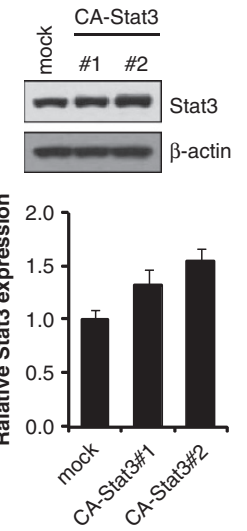

b

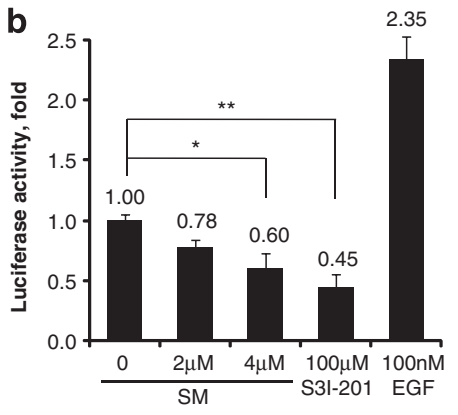

f

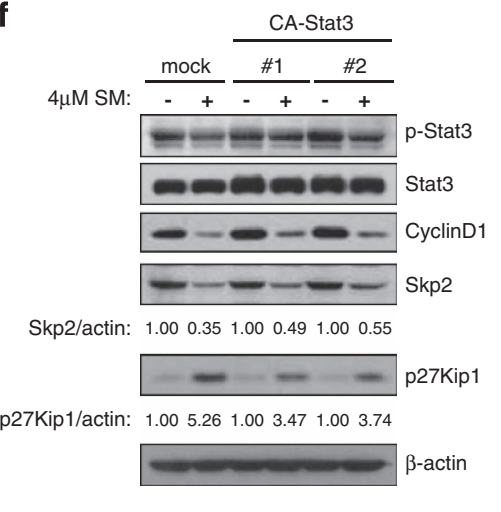

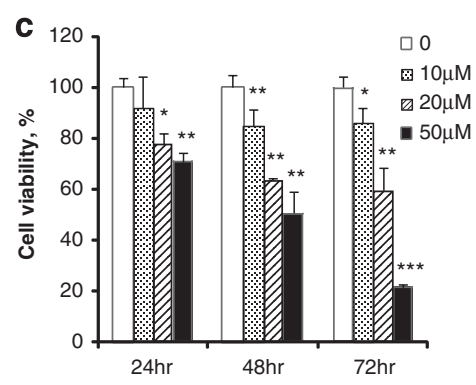

g

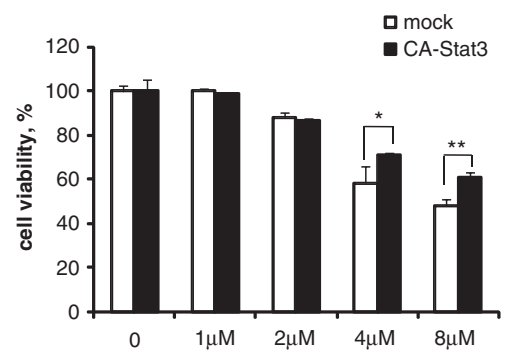

Figure 4 Salinomycin inhibits phosphorylation and transcriptional activity of Stat3. (a) Cells were treated without or with $4 \mu \mathrm{M}$ salinomycin for $24 \mathrm{~h}$, and equal amounts of cell lysates were subjected to immunoblot analysis using the indicated antibodies. (b) The Stat3-dependent luciferase reporter construct pZLuc-TK or the control luciferase reporter PGL-3 was transfected into the DXR cells. After $24 \mathrm{~h}$ of transfection, cells were treated with 0, 2, or $4 \mu \mathrm{M}$ salinomycin (24 h), $100 \mu \mathrm{M} \mathrm{S3I-201} \mathrm{(16} \mathrm{h),} \mathrm{or} 100 \mathrm{nM}$ EGF $(3 \mathrm{~h})$, and luciferase activity was analyzed. EGF treatment was used as a positive activator of Stat3. The fold change in relative luciferase activity in the untreated control cells was set as 1. Data are presented as averages of triplicate measurements, with error bars representing standard deviations. ${ }^{*} P<0.05$ and ${ }^{* *} P<0.005$. (c) DXR cells were treated with indicated concentrations of S3I-201, and cell viability was assessed by MTS assay. Data are presented as averages of triplicate measurements, with error bars representing standard deviations. ${ }^{*} P<0.05,{ }^{* *} P<0.005$, and ${ }^{* *} P<0.0005$. (d) DXR cells were treated with the indicated concentration of S3I-201 for $16 \mathrm{~h}$, and equal amounts of cell lysates were subjected to immunoblot analysis using the indicated antibodies. (e) DXR cells were transfected with mock or CA-Stat3 constructs at two different times (no. 1 and no. 2) and selected to get stable cell populations. Stat3 expression levels were determined by immunoblot analysis (upper panel) and qPCR (lower panel). Data are presented as averages of triplicate measurements, with error bars representing standard deviations. (f) Mock cells and CA-Stat3-expressing cells (no. 1 and no. 2) were treated without or with $4 \mu \mathrm{M}$ salinomycin for $24 \mathrm{~h}$, and equal amounts of cell lysates were subjected to immunoblot analysis using the indicated antibodies. $\beta$-Actin was a loading control. The levels of Skp2 and p27Kip1 were quantified by densitometry and normalized to $\beta$-actin levels. The ratios of Skp2 and p27Kip1 to total $\beta$-actin in the untreated cells were set as 1. Similar results were observed in two independent experiments. (g) Mock and CA-Stat3 (no. 2) cells were treated with 0-8 $\mu \mathrm{M}$ salinomycin for $72 \mathrm{~h}$, and cell growth inhibition was determined by MTS assay. Data are presented as averages of triplicate measurements, with error bars representing standard deviations ${ }^{*} P<0.05$ and ${ }^{* \star} P<0.005$

for control (si-Cont) (Figure 6d). Cdh1 knockdown by siRNA also decreased salinomycin-induced Skp2 ubiquitination (Figure 6e). Consequently, salinomycin-induced G1 population was increased up to $73 \%$, but this G1 arrest was blocked to $52 \%$ when Cdh1 was knocked down (Figure 6f). Taken together, these data indicate that salinomycin inhibits cell growth and induces apoptosis through Skp2 destabilization by Stat3 inactivation and by an APC ${ }^{\text {Chn } 1}$-mediated pathway, leading to p27Kip1 accumulation.

\section{Discussion}

Cancer cells possess numerous mechanisms of resistance to chemotherapeutic drugs, allowing them to escape current cancer therapies. Recent reports indicate that CSCs are resistant to chemotherapy and thus responsible for cancer recurrence after chemotherapy. ${ }^{4}$ Salinomycin has recently been identified as an inhibitor to control selectively CSC-like cells in some tumor types, including breast cancer and leukemia, ${ }^{6,8-12}$ although the underlying mechanisms are not well elucidated. Here, we demonstrate that salinomycin induces cell growth inhibition and apoptosis via Stat3-cyclin D1 and APC Cdh1-Skp2-p27Kip1 pathway-dependent cell cycle arrest at $\mathrm{G} 1$ phase in both drug-sensitive and multidrug-resistant cancer cell lines (Figure 7).

Drug resistance is one of the characteristics of CSCs due to high expression of MDR-1. ${ }^{4}$ Some studies have demonstrated that salinomycin is an MDR-1 inhibitor ${ }^{13}$ and that it can sensitize cancer cells to other anticancer reagents. ${ }^{17}$ In our study, we found that salinomycin itself exerted cell growth inhibition and apoptosis in both drug-sensitive and drugresistant cell lines, indicating that salinomycin is not a substrate of MDR-1 (Figure 1). In addition, MDR-1 mRNA levels decreased at $24 \mathrm{~h}$ of salinomycin treatment, but its protein levels decreased at $72 \mathrm{~h}$ treatment (Supplementary Figures 4a-c). Accordingly, MDR-1 activity assessed by rhodamine123 efflux decreased at $72 \mathrm{~h}$ treatment (Supplementary Figure 4d). Because we observed cell cycle 
a
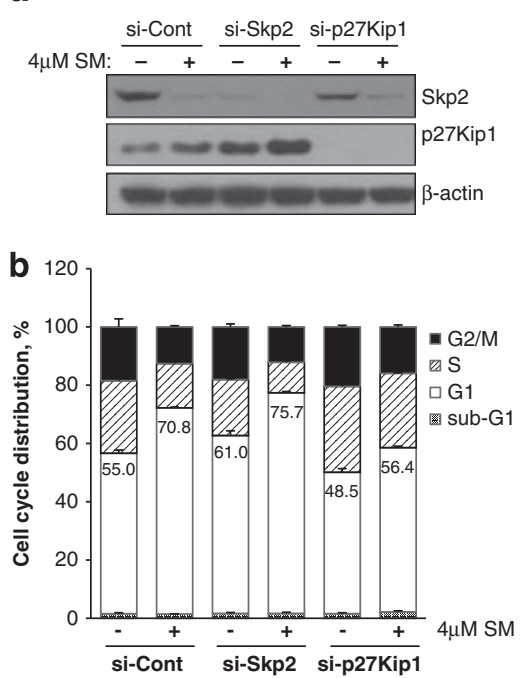

C

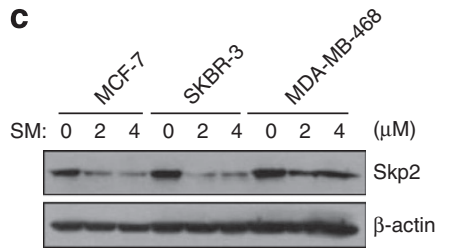

d

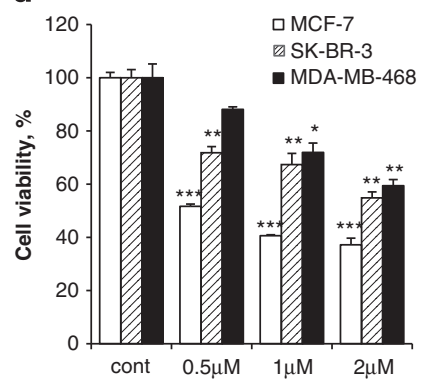

e
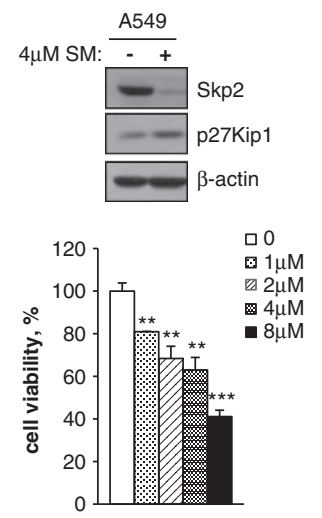

Figure 5 Effects of expression level of Skp2 or p27Kip1 on salinomycin-induced G1 cell cycle arrest and cell growth inhibition. (a) DXR cells were transfected with si-Cont, Skp2, or p27Kip1. After $24 \mathrm{~h}$ of transfection, cells were treated without or with $4 \mu \mathrm{M}$ salinomycin for $24 \mathrm{~h}$, and equal amounts of cell lysates were subjected to immunoblot analysis using the indicated antibodies. (b) DXR cells were transfected with siRNA and then treated with salinomycin as in panel a, and cell cycle was analyzed by flow cytometer. The percentage of cells in G1 phase is annotated in each column. Data are presented as averages of triplicate measurements, with error bars representing standard deviations. These experiments were performed three times with comparable results. (c) MCF-7, SK-BR-3, and MDA-MB-468 cells were treated with 0-4 $\mu \mathrm{M}$ salinomycin for $24 \mathrm{~h}$, and equal amounts of cell lysates were subjected to immunoblot analysis using the indicated antibodies. (d) MCF-7, SK-BR-3, and MDA-MB-468 cells were treated with $0-2 \mu \mathrm{M}$ salinomycin for $72 \mathrm{~h}$, and cell survival was determined by MTS assay. Data are presented as averages of triplicate measurements, with error bars representing standard deviations. These experiments were performed three times with comparable results. ${ }^{*} P<0.05$, ${ }^{* *} P<0.005$, and ${ }^{* *} P<0.0005$. (e) A549 cells were treated without or with $4 \mu \mathrm{M}$ salinomycin for $24 \mathrm{~h}$, and equal amounts of cell lysates were subjected to immunoblot analysis using the indicated antibodies (upper panel). A549 cells were treated with 0-8 $\mu \mathrm{M}$ salinomycin for $72 \mathrm{~h}$, and cell survival was determined by MTS assay (lower panel). Data are presented as averages of triplicate measurements, with error bars representing standard deviations. These experiments were performed three times with comparable results ${ }^{\star \star} P<0.005$ and ${ }^{\star \star \star} P<0.0005$

arrest at $24 \mathrm{~h}$ of salinomycin treatment, it is likely that salinomycin induces cell cycle arrest and apoptosis regardless of MDR- 1 expression.

Cell cycle progression and transitions in mammalian cells are regulated by a subfamily of CDKs, the activity of which is modulated by several positive regulators (cyclins) and negative regulators (inhibitors). ${ }^{21}$ The G1/S-phase transition is critical for cell cycle progression, and dysregulation of cyclins and CDKs has been linked to cancer. For example, cyclin D1 is important for G1 progression and promotes cell proliferation as an activator for CDK4 and CDK6. ${ }^{21}$ Cyclin D1 is overexpressed in several cancers and is a biomarker of cancer phenotype and disease progression, indicating that targeting of cyclin D1 oncogenes appears to be an attractive therapeutic strategy. ${ }^{25}$ As negative regulators of the G1/S-phase transition, p21Cip1/p27Kip1 and the INK4 proteins are inhibitors of CDKs, and upregulation of p21Cip1/p27Kip1 is known to cause growth inhibition in various cancer types. $^{20,26}$ In this regard, our study demonstrates that salinomycin downregulates cyclin D1 and upregulates p27Kip1, leading to cell growth inhibition through G1 arrest.

Stat3 is one of the transcription factors for cyclin D1, and Stat3 is activated in various cancers, including ovarian cancer. ${ }^{40,47}$ It has been reported that aberrant Stat3 activation promotes uncontrolled tumor cell growth and survival through multiple mechanisms, including increased expression of oncogenes, such as c-myc, Skp2, and cyclin D1, as well as antiapoptotic proteins, including Bcl-2, Bcl-xL, Mcl-1, and survivin. ${ }^{41,42,48}$ Stat3 activation is not only essential for cell survival but also required for cell cycle transition. ${ }^{49}$ Recently, Stat3 is known to regulate growth and self-renewal of glioblastoma stem cells, ${ }^{50}$ and cyclin D1 is important for self-renewal of mammary stem and progenitor cells that are targets of MMTV-ErbB2 tumorigenesis. ${ }^{51}$ Therefore, interfering with the Stat3 oncogenic pathway might restore sensitivity to anticancer drugs. Here, we have illustrated that salinomycin decreases Stat3 phosphorylation and transcription activity and thus downregulates expression of Stat3 target genes, such as cyclin D1, Skp2, and survivin (Figure 4 and Supplementary Figure 2), although c-myc levels remain unchanged (Supplementary Figure 5). Treatment with S3I-201, a Stat3 inhibitor, resulted in Stat3 inactivation and cyclin D1 downregulation, which is similar to the effects by salinomycin (Figures 4c and d). However, salinomycin still downregulated cyclin D1 in the CA-Stat3-expressing cells (Figure $4 \mathrm{e}$ and Supplementary Figure 2). It is possible that salinomycin is a powerful negative regulator of cyclin D1 independent of Stat3 activity. This could explain why CA-Stat3 expression partially protected cells from salinomycin-induced growth inhibition.

Among the CDK inhibitors, p27Kip1 is a potent negative regulator of G1-specific CDK-cyclin complexes. Mice lacking p27Kip1 display multi-organ hyperplasia and are susceptible to carcinogen-induced tumors, indicating that p27Kip1 is a tumor suppressor. ${ }^{52}$ The loss of p27Kip1 protein has been found in numerous cancers, and decreased levels of p27Kip1 are associated with shorter disease-free and/or overall survival. ${ }^{26}$ Notably, salinomycin upregulated p27Kip1, and 
a

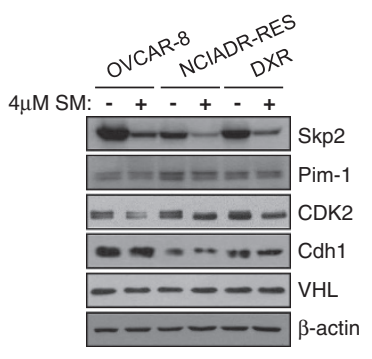

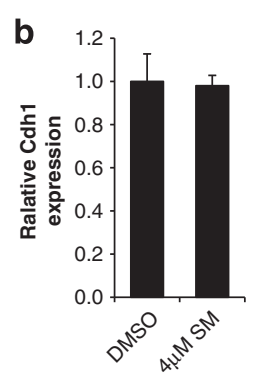

e

d

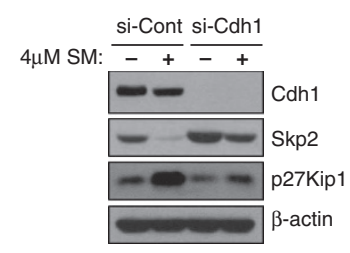

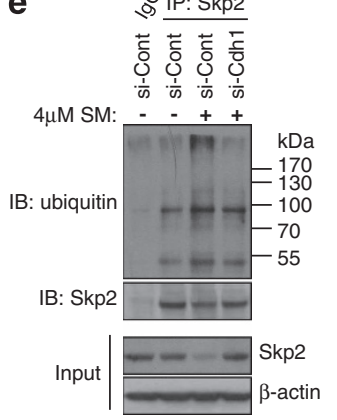

C
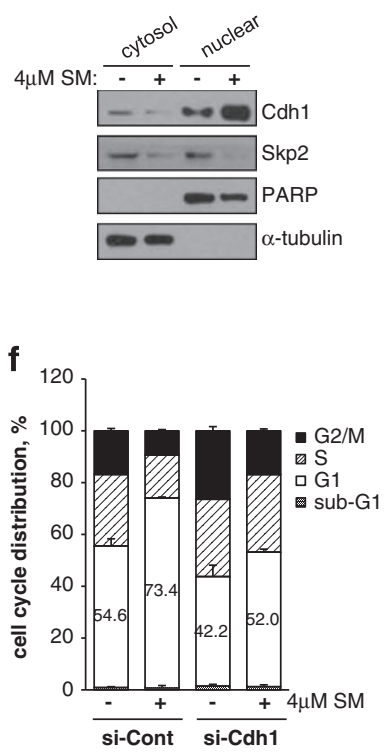

Figure 6 Regulation of salinomycin-induced Skp2 degradation in DXR cells. (a) Cells were treated without or with $4 \mu \mathrm{M}$ salinomycin for $24 \mathrm{~h}$, and equal amounts of cell lysates were subjected to immunoblot analysis using the indicated antibodies. (b) DXR cells were treated without or with $4 \mu \mathrm{M}$ salinomycin for $24 \mathrm{~h}$, and the levels of Cdh1 mRNA were determined by qPCR. The levels of Cdh1 mRNA were normalized to mRNA levels of GAPDH and B2M. (c) DXR cells were treated without or with $4 \mu \mathrm{M}$ salinomycin for $24 \mathrm{~h}$, and cell lysates were separated into cytosolic and nuclear fractions. Protein samples of cytosolic and nuclear fractions were analyzed by immunoblot analysis using the indicated antibodies. PARP and $\alpha$-tubulin were used as controls for the nuclear and cytosolic fractions, respectively. (d) DXR cells were transfected with si-Cont or si-Cdh1 for $24 \mathrm{~h}$ and treated without or with $4 \mu \mathrm{M}$ salinomycin for $24 \mathrm{~h}$. Equal amounts of cell lysates were subjected to immunoblot analysis using the indicated antibodies. (e) DXR cells were treated as in panel $\mathbf{d}$, and cell lysates were subjected to immunoprecipitation using anti-Skp2 or normal rabbit IgG antibodies. Immunoprecipitates were processed for immunoblot analysis using ubiquitin and Skp2 antibodies. (f) DXR cells were treated as in panel d, followed by cell cycle analysis. The percentage of cells in G1 phase is annotated in each column. Data are presented as averages of triplicate measurements, with error bars representing standard deviations. These experiments were performed three times and yielded comparable results

knockdown of p27Kip1 using siRNA reversed salinomycininduced $\mathrm{G} 1$ arrest (Figures $3 \mathrm{a}$ and $5 \mathrm{~b}$ ), indicating that p27Kip1 upregulation is critical for $\mathrm{G} 1$ arrest induced by salinomycin. The levels of p27Kip1 protein are largely controlled by ubiquitin-dependent proteolysis, and a major pathway for p27Kip1 turnover involves its recognition by Skp2, a critical component of the SCF E3 ligase complex. ${ }^{22}$

Skp2 targets cell cycle-negative regulators, such as p27Kip1, p21Cip1, p130Cas, and FOX01, for proteasomal degradation, ultimately positively affecting cell cycle progression. ${ }^{29,53}$ Levels of Skp2 are inversely correlated with p27Kip1 expression, and overexpression of Skp2 is frequently observed in numerous human cancers. ${ }^{27,30,31}$ Skp2 expression has been considered as a biomarker of poor prognosis for breast cancer, melanoma, and nasopharyngeal carcinoma. ${ }^{32,54,55}$ Interestingly, a recent study revealed a possible role for Skp2 in maintaining the CSC-like phenotype of nasopharyngeal carcinoma cells. ${ }^{56}$ Because of its oncogenic activity and its role in cancer development, Skp2 has been suggested as a novel and attractive therapeutic target for the cancer treatment. In this study, we found that salinomycin downregulates Skp2 levels and inversely stabilizes p27Kip1 in multiple cancer cell lines, including ovarian cancer, breast cancer, lung cancer, and glioma cell lines (Figures 3a, 5c, and $5 \mathrm{e}$, and data not shown). Skp2 knockdown by siRNA further upregulated p27Kip1 and potentiated salinomycininduced G1 arrest, indicating that the Skp2-p27Kip1 pathway is an important pathway to cell growth inhibition by salinomycin.
In addition to regulating its gene expression, Skp2 is regulated by protein stability through multiple pathways, including phosphorylation, subcellular localization, and proteasomal degradation. ${ }^{41,43-46}$ In our study, salinomycin appeared to downregulate Skp2 at post-translational levels rather than the transcriptional level because the proteasomal inhibitor MG132 could reverse Skp2 downregulation (Figure 3e). Skp2 ubiquitination is triggered by the E3 ubiquitin ligase APC/Cdh1 complex and results in Skp2 degradation. ${ }^{33}$ Recently, it was reported that Skp2 is phosphorylated by $\mathrm{Akt}^{44}$ and $\mathrm{CDK}^{45}$ at $\mathrm{Ser}^{72}$ and $\mathrm{Ser}^{64}$, respectively. The phosphorylation of Skp2 on these residues disrupts the interaction between Cdh1 and Skp2, thereby inhibiting Skp2 ubiquitination by Cdh1 and proteasomal degradation. ${ }^{45}$ Although salinomycin inactivates Akt in OVCAR-8, $\mathrm{NCl} / \mathrm{ADR}-\mathrm{RES}$, and DXR cells (Figure 2e), Akt inactivation appears not to affect Skp2 degradation because Skp2 degradation precedes Akt inactivation (Supplementary Figure 6). CDK2 could be associated with Skp2 degradation because CDK2 levels were decreased by salinomycin treatment (Figure 6a), although we did not examine Skp2 phosphorylation. More interestingly, salinomycin treatment increased levels of Cdh1 in the nuclear fraction, where Cdh1 ubiquitinates Skp2 for proteasomal degradation. Consistent with this notion, Skp2 in the nuclear fractions as well as in the cytosol was decreased with salinomycin treatment (Figure 6b). In addition, salinomycin-induced Skp2 downregulation was attenuated by Cdh1 knockdown using 


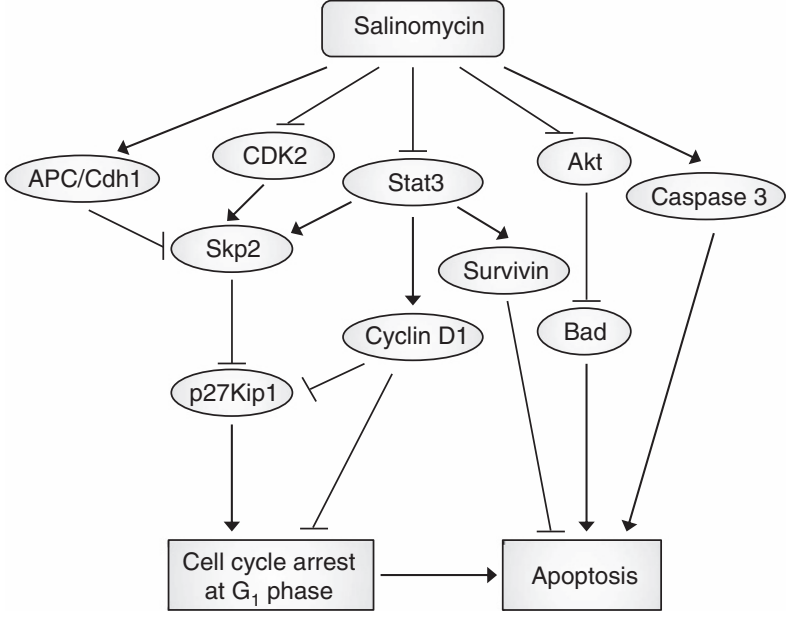

Figure 7 Schematic model of signaling pathways in salinomycin-induced cell growth inhibition and apoptosis. Salinomycin exerts its antitumor effects by inhibition of oncogenic proteins such as Stat3, cyclin D1, and Skp2 but upregulates the tumor suppressor p27Kip1. Salinomycin inhibits Stat3 activation and thus decreases transcription of its target proteins, including cyclin D1 and survivin, which are important for cell cycle progression and cell survival. Salinomycin activates the APC/Cdh1-Skp2-p27Kip1 pathway, leading to degradation of Skp2 and thus accumulation of the cell cycle inhibitor p27Kip1, which culminates in cell cycle arrest. Salinomycin also activates apoptosis signaling pathways including Akt inactivation and caspase-3 activation, which leads to cell death

si-Cdh1 RNA. Consequently, salinomycin-induced G1 arrest was reversed by Cdh1 knockdown. The ability of salinomycin to control Skp2 levels is of importance because Skp2 is an oncogene and is overexpressed in most tumors. Recently, it was reported that salinomycin acts as a potent inhibitor of Wnt proximal signaling and decreases levels of $\beta$-catenin in chronic lymphocytic leukemia cells. ${ }^{19}$ However, $\beta$-catenin levels remained unchanged with salinomycin treatment in all three cell lines (Supplementary Figure 7).

In conclusion, our results provide evidence that salinomycin is able to downregulate the oncoprotein Skp2 and upregulate the tumor suppressor protein p27Kip1, thereby inducing cell cycle arrest at $\mathrm{G}_{1}$ phase and apoptosis. In addition, salinomycin inactivates Stat3 and downregulates cyclin D1, which are important for self-renewal of CSCs. Therefore, salinomycin or its derivatives could be considered as novel anticancer agents that target Skp2 and Stat3 to induce apoptosis of both drug-sensitive and drug-resistant cancer cells.

\section{Materials and Methods}

Cell culture. Human ovarian carcinoma cell lines OVCAR-8 and NCI/ADR-RES, which are multidrug-resistant cells derived from OVCAR- $8,{ }^{37}$ were both obtained from the National Cancer Institute (Rockville, MD, USA) and cultured in RPMI 1640 (Hyclone, Rockford, IL, USA) supplemented with 10\% fetal bovine serum (Hyclone) and $1 \%$ penicillin and streptomycin (Invitrogen, San Diego, CA, USA) in a $5 \% \mathrm{CO}_{2}$ atmosphere at $37^{\circ} \mathrm{C}$. Doxorubicin-resistant subcell line (DXR) was selected in stepwise increasing concentrations of doxorubicin from NCI/ADR-RES cells. DXR cells were obtained, which were able to survive in $50 \mu \mathrm{M}$ doxorubicin, and thereafter maintained in culture media containing $1 \mu \mathrm{M}$ doxorubicin prior to their use in studies. Breast cancer cell lines, MCF-7, SK-BR-3, and MDA-MB-468, and A549 lung cancer cell line were purchased from American Type Culture Collection (ATCC, Manassas, VA, USA) and cultured in RPMI 1640 (Hyclone) supplemented with 10\% fetal bovine serum (Hyclone) and 1\% penicillin and streptomycin (Invitrogen).
Antibodies and reagents. Salinomycin, doxorubicin, paclitaxel, cisplatin, etoposide, rhodamine123, and anti- $\beta$-actin were purchased from Sigma (St. Louis, MO, USA). Salinomycin was dissolved in DMSO to make a $10 \mathrm{mM}$ stock solution and was added directly to the culture media. MG132, S3I-201, CHX, and anti-Cdh1 were purchased from Calbiochem (La Jolla, CA, USA). Horseradish peroxidase (HRP)-conjugated goat anti-mouse IgG, HRP-conjugated goat anti-rabbit IgG, anti-MDR-1, anti-CDK1, anti-cyclin A, anti-Bcl-xL, anti-Bax, anti-survivin, and anti-Skp2 (for immunoprecipitation, sc-7164) antibodies were purchased from Santa Cruz Biotechnology (Santa Cruz, CA, USA). Anti-Skp2 (for immunoblotting, CS no. 4358), a conformation-specific mouse anti-rabbit lgG (CS no. 3678), anti-p27Kip1, anti-p21Cip1, anti-p16INK4A, anti-p15INK4B, anti-cyclin D1, anti-CDK2, anti-CDK4, anti-CDK6, anti-phospho-Akt (S473), anti-Akt, anti-phospho-Stat3 (Y705), anti-Stat3, anti-phospho-Bad (S136), anti-livin, anti-c-IAP1, anti-c-IAP2, anti-XIAP, anti-caspase-3, anti-PARP, and anti-Pim-1 antibodies were obtained from Cell Signaling Technology (Beverly, MA, USA). Anti-GAPDH was purchased from Abfrontier (Seoul, Republic of Korea). Anti-VHL was from BD Pharmingen (San Diego, CA, USA). Chemiluminescent reagents were obtained from GE Healthcare (Buckinghamshire, UK) and Animal Genetics Inc. (Tallahassee, FL, USA).

Cell viability and cytotoxicity. Cells were plated at a density of $2 \times 10^{3}$ cells per well into a 96-well plate. One day ( $24 \mathrm{~h})$ after seeding, drugs were added in triplicates per concentration for each cell line. Cell viability and cytotoxicity were measured after $72 \mathrm{~h}$ with the CellTiter96 Aqueous Non-Radioactive Assay (Promega, Madison, WI, USA) as described in the manufacturer's instruction. Briefly, $20 \mu \mathrm{l}$ of the MTS solution was added to each well, and the plates were incubated for another $3 \mathrm{~h}$. The absorbance at $490 \mathrm{~nm}$ was measured using PowerWave HT microplate spectrophotometer (BioTek Instruments Inc., Winooski, VT, USA). For cell counting, cells were plated at a density of $1 \times 10^{5}$ cells per well into a six-well plate. One day after seeding, $4 \mu \mathrm{M}$ salinomycin and equivalent DMSO were added. After treatment, cells were incubated for 6 days, and media were changed with fresh media in every 2 days. Cells were counted using Z1 coulter particle counter (Beckman Coulter, Brea, CA, USA) every day.

Colony-forming assay. OVCAR-8 and DXR cells were seeded in six-well plates $\left(2 \times 10^{5}\right.$ cells per well) and incubated for $24 \mathrm{~h}$. Cells were treated without or with $4 \mu \mathrm{M}$ salinomycin for $72 \mathrm{~h}$. Cells were then harvested, replated into six-well plates $\left(1 \times 10^{3}\right.$ cells per well) in the absence of salinomycin, and incubated for 10 days. Colonies were stained with crystal violet, and images were taken by Kodak Image Station 2000R (Eastman Kodak Company, New Haven, CT, USA).

Rhodamine123 efflux and doxorubicin accumulation. Cells were incubated with either $10 \mu \mathrm{M}$ rhodamine123 or $50 \mu \mathrm{M}$ doxorubicin for $2 \mathrm{~h}$. Thereafter, cells were washed in phosphate-buffered saline (PBS), and the fluorescence intensity of rhodamine123 or doxorubicin was detected by flow cytometry.

Flow cytometric analysis. Cells were seeded in six-well plates and incubated for $24 \mathrm{~h}$ before treatment and then $4 \mu \mathrm{M}$ salinomycin and equivalent were added. Cells were harvested at 24,48 , and $72 \mathrm{~h}$ following treatment. For cell cycle analysis, harvested cells were washed with prechilled PBS and were fixed with $70 \%$ ethanol and stored at $4^{\circ} \mathrm{C}$ for overnight. Cells were rehydrated with PBS for $10 \mathrm{~min}$, and then cells were stained with PI staining solution containing $50 \mu \mathrm{g} / \mathrm{ml} \mathrm{Pl}, 2 \mu \mathrm{g} / \mathrm{ml}$ DNase-free RNase A, and $0.2 \% \mathrm{NP}-40$ in PBS for $15 \mathrm{~min}$ at $37^{\circ} \mathrm{C}$. Finally, cell cycle analysis was performed. For detection of apoptotic cells, harvested cells were washed twice with prechilled PBS and resuspended in $100 \mu \mathrm{l}$ binding buffer at a concentration of $1 \times 10^{6} \mathrm{cells} / \mathrm{ml}$. Annexin V and PI double staining was performed using the Annexin V-FITC Apoptosis Detection Kit (BD Biosciences, San Jose, CA, USA) as described by the manufacturer's protocol. All flow cytometric analysis was performed by FACSCalibur (BD Biosciences), and the raw data were analyzed by Cell Quest Software (BD Biosciences) in flow cytometry core facility of the National Cancer Center (Goyang, Republic of Korea).

Establishment of stable transfected cells. CA-Stat3/pcDNA3 construct was a kind gift from Dr. Sang Kyu Ye (Seoul National University, Seoul, Republic of Korea) and was described previously. ${ }^{48}$ DXR cells were transfected with CA-Stat3/pcDNA3 or mock vector plasmids using Lipofectamine 2000 reagent (Invitrogen) for $24 \mathrm{~h}$ and selected with $\mathrm{G} 418(250 \mu \mathrm{g} / \mathrm{ml})$ for 2 weeks 
to establish stable cell lines. Selected cells were maintained in the media containing G418 $(100 \mu \mathrm{g} / \mathrm{ml})$.

siRNA preparation and transfection. Validated siRNA duplex of human Skp2 (1137712), p27Kip1 (1029382), Cdh1 (1059777), and the negative control with scrambled sequence (SN1003) were from Bioneer (Daejeon, Republic of Korea). For RNA interference, DXR cells were transfected with $50 \mathrm{nM}$ siRNA using Lipofectamine RNAiMAX reagent (Invitrogen) by reverse transfection according to the manufacturer's protocol. After $24 \mathrm{~h}$ of transfection, the DXR cells were treated with either DMSO or $4 \mu \mathrm{M}$ salinomycin. Knockdown efficiency and specificity of each siRNA was confirmed using immunoblotting with corresponded antibodies.

Luciferase assays. The pZLuc-TK vector contains three copies of Stat-binding sites in a Ly6E promoter. ${ }^{57}$ The $3 x$ Ly6E/pZLuc-TK and pGL-3 (Promega) luciferase reporter plasmids were transfected into DXR cell lines using Lipofectamine 2000 reagent (Invitrogen). Luciferase activity was assayed using the Dual-Luciferase Assay kit (Promega) according to the instructions of the manufacturer. Luciferase activity was measured using VICTOR Light Luminescence counter (Perkin Elmer, Shelton, CT, USA), and the data were normalized based on the same level of proteins and expressed as the fold induction over control cells.

Cytosolic and nuclear extraction. After washing with ice-cold PBS, cells were harvested by scraping and centrifuged at $4^{\circ} \mathrm{C}$ for $10 \mathrm{~s}$, and PBS was removed completely. Cell pellet was resuspended in $200 \mu$ l of Solution A (10 mM HEPES (pH 7.9), $1.5 \mathrm{mM} \mathrm{MgCl}_{2}$, and $10 \mathrm{mM} \mathrm{KCl}$ ) with protease inhibitors and left on ice for $5 \mathrm{~min}$. A portion of $12.5 \mu \mathrm{l}$ of $10 \% \mathrm{NP}-40$ was added into the mixture by dropping and was mixed immediately and then was centrifuged at $4^{\circ} \mathrm{C}$ for $30 \mathrm{~s}$. The supernatant was used to cytosolic fraction, and the pellet was washed twice with Solution A. Washed cell pellet was resuspended in $50 \mu \mathrm{l}$ of Solution C $(20 \mathrm{mM}$ HEPES (pH 7.9), $1.5 \mathrm{mM} \mathrm{MgCl}_{2}, 0.42 \mathrm{M} \mathrm{NaCl}, 0.2 \mathrm{mM}$ EDTA, and $25 \%$ glycerol) with protease inhibitors by several pipetting right immediately and was extracted at $4^{\circ} \mathrm{C}$ for 60 min using a rotating mixer. Cell mixture was centrifuged at $4^{\circ} \mathrm{C}$ for $10 \mathrm{~min}$, and the supernatant was used to nuclear fraction. Protein samples of cytosolic and nuclear fraction were analyzed by immunoblotting.

Immunoblot analysis. After washing with ice-cold PBS, cells were lysed with $2 \times$ SDS-PAGE sample buffer ( $20 \mathrm{mM}$ Tris (pH 8.0), $2 \%$ SDS, $2 \mathrm{mM}$ DTT, $1 \mathrm{mM} \mathrm{Na}_{3} \mathrm{VO}_{4}, 2 \mathrm{mM}$ EDTA, and $20 \%$ glycerol) and boiled for $5 \mathrm{~min}$. Protein concentration of each sample was determined using a BCA protein assay reagent (Pierce, Rockford, IL, USA) as described by the manufacturer. In all, 20-50 $\mu \mathrm{g}$ of total cellular protein was separated by $10-15 \%$ SDS-PAGE and then transferred to nitrocellulose membranes (Millipore, Bedford, MA, USA). The membranes were blocked for $30 \mathrm{~min}$ at room temperature in Tris-buffered saline and Tween 20 (TBS-T; $20 \mathrm{mM}$ Tris (pH 8.0), $150 \mathrm{mM} \mathrm{NaCl}$, and 0.05\% Tween 20) containing 5\% non-fat dried milk. The membranes were then incubated with the primary antibody for overnight at $4^{\circ} \mathrm{C}$, washed three times with TBS-T, incubated with HRP-conjugated goat anti-mouse IgG or goat anti-rabbit lgG secondary antibodies for $1 \mathrm{~h}$ at room temperature, and then washed with TBS-T three times. The labeled proteins were visualized using the enhanced chemiluminescence method. The film was scanned, and the protein bands were quantified by the densitometric analysis using ImageJ software (http://rsb.info.nih.gov/ij/).

Immunoprecipitation. After washing with ice-cold PBS, cells were lysed with immunoprecipitation assay (IPA) buffer (20 mM Tris (pH 7.5), $150 \mathrm{mM} \mathrm{NaCl}$, $1 \mathrm{mM}$ EDTA, $1 \mathrm{mM}$ EGTA, 1\% Triton X-100, $2.5 \mathrm{mM}$ sodium pyrophosphate, $1 \mathrm{mM}$ $\beta$-glycerophosphate, $1 \mathrm{mM} \mathrm{Na} \mathrm{VO}_{4}, 1 \mu \mathrm{g} / \mathrm{ml}$ leupeptin, $1 \mu \mathrm{g} / \mathrm{ml}$ aprotinin, and $1 \mathrm{mM}$ PMSF). The cell lysates were centrifuged at $4{ }^{\circ} \mathrm{C}$ for $10 \mathrm{~min}$ at 14000 r.p.m., and $1 \mathrm{mg}$ protein of the supernatants was precleared by incubating with protein A/G-conjugated agarose beads at $4{ }^{\circ} \mathrm{C}$ for $1 \mathrm{~h}$, followed by centrifugation at $4{ }^{\circ} \mathrm{C}$ for $1 \mathrm{~min}$ at 14000 r.p.m. The supernatants were then subjected to immunoprecipitation using $2 \mu \mathrm{g}$ of anti-Skp2 antibody or normal rabbit IgG and an overnight incubation at $4{ }^{\circ} \mathrm{C}$ followed by incubation with protein $\mathrm{A} / \mathrm{G}$-conjugated agarose beads for $2 \mathrm{~h}$ at $4{ }^{\circ} \mathrm{C}$. After washing the beads five times with ice-cold IPA buffer, the bound proteins were eluted with SDS-PAGE sample buffer and subjected to electrophoresis and immunoblot analysis. Immunoprecipitated Skp2 was detected using a conformation-specific mouse anti-rabbit $\lg G$ and goat anti-mouse $\lg G$ HRP-linked antibody.
Reverse transcription PCR and quantitative real-time RT-PCR. Total cellular RNA was isolated with Trizol reagent (Invitrogen) according to the manufacturer's instructions. Single-stranded complementary DNA (cDNA) was generated using Maxime RT PreMix (Oligo $\mathrm{dT}_{15}$ Primer) (iNtRON Biotechnology, Sungnam, Republic of Korea) following the manufacturer's directions. Obtained cDNA was amplified using specific primers. The primers were as follows: MDR-1, $5^{\prime}$-GTTACTCTTAGCAATTGTACCCATCAT- $3^{\prime}$ (forward) and 5'-CAAAGACAA CAGCTGAAATACTAACA-3' (reverse); $\beta$-actin, $5^{\prime}$-ACAACGGCTCCGGCATGTG CAA-3' (forward) and 5'-CGGTTGGCCTTGGGGTTCAG-3' (reverse); GAPDH, $5^{\prime}$-CTTGGTATCGTGGAAGGA-3' (forward) and 5'-CACCCTGTTGCTGTAGCC-3' (reverse). PCR experiments were performed in TGradient Thermal Cycler (Biometra, Goettingen, Germany) using AccuPower PCR Premix (Bioneer) according to the manufacturer's protocol.

Quantitative real-time PCR was performed in CFX96 Real Time System (Bio-Rad, Hercules, CA, USA) using Rotor-Gene SYBR Green PCR Kit (Qiagen, Hamburg, Germany). Validated primers of Skp2 (P215761), cyclin D1 (P298560), Cdh1 (P291733), Stat3 (P229000), GAPDH (P267613), and B2M (110309) were purchased from Bioneer. All reactions were performed in triplicates, and the relative transcript abundance of each tested gene was normalized to the expression levels of dual housekeeping genes, GAPDH and B2M ( $\beta 2$-microglobulin).

Statistics. Summary statistics are presented as the mean \pm S.D. Where appropriate, data were evaluated by performing a simple comparison between two values using Student's $t$-test. A $P$-value of $<0.05$ was considered statistically significant.

\section{Conflict of Interest}

The authors declare no conflict of interest.

Acknowledgements. This study was supported by the National Research Foundation of Korea (NRF) funded by the Ministry of Education, Science and Technology (2009-007761) and by the National Cancer Center (0910050).

1. Gottesman MM, Fojo T, Bates SE. Multidrug resistance in cancer: role of ATP-dependent transporters. Nat Rev Cancer 2002; 2: 48-58.

2. Clarke MF, Dick JE, Dirks PB, Eaves CJ, Jamieson CH, Jones DL et al. Cancer stem cells-perspectives on current status and future directions: AACR Workshop on cancer stem cells. Cancer Res 2006; 66: 9339-9344.

3. Ward RJ, Dirks PB. Cancer stem cells: at the headwaters of tumor development. Annu Rev Pathol 2007; 2: 175-189.

4. Dean M, Fojo T, Bates S. Tumour stem cells and drug resistance. Nat Rev Cancer 2005; 5: 275-284.

5. Li F, Tiede B, Massague J, Kang Y. Beyond tumorigenesis: cancer stem cells in metastasis. Cell Res 2007; 17: 3-14.

6. Gupta PB, Onder TT, Jiang G, Tao K, Kuperwasser C, Weinberg RA et al. Identification of selective inhibitors of cancer stem cells by high-throughput screening. Cell 2009; 138: 645-659.

7. Miyazaki $Y$, Shibuya M, Sugawara H, Kawaguchi O, Hirsoe C. Salinomycin, a new polyether antibiotic. J Antibiot (Tokyo) 1974; 27: 814-821.

8. Fuchs D, Daniel V, Sadeghi M, Opelz G, Naujokat C. Salinomycin overcomes ABC transporter-mediated multidrug and apoptosis resistance in human leukemia stem cell-like KG-1a cells. Biochem Biophys Res Commun 2010; 394: 1098-1104.

9. Dong TT, Zhou HM, Wang LL, Feng B, Lv B, Zheng MH. Salinomycin selectively targets 'CD133 + ' cell subpopulations and decreases malignant traits in colorectal cancer lines. Ann Surg Oncol 2011; 18: 1797-1804.

10. Wang Y. Effects of salinomycin on cancer stem cell in human lung adenocarcinoma a549 cells. Med Chem 2011; 7: 106-111.

11. Zhi QM, Chen XH, Ji J, Zhang JN, Li JF, Cai $Q$ et al. Salinomycin can effectively kill ALDH(high) stem-like cells on gastric cancer. Biomed Pharmacother 2011; 65: 509-515.

12. Tang QL, Zhao ZQ, Li JC, Liang Y, Yin JQ, Zou CY et al. Salinomycin inhibits osteosarcoma by targeting its tumor stem cells. Cancer Lett 2011; 311: 113-121.

13. Riccioni R, Dupuis ML, Bernabei M, Petrucci E, Pasquini L, Mariani G et al. The cancer stem cell selective inhibitor salinomycin is a p-glycoprotein inhibitor. Blood Cells Mol Dis 2010; 45: 86-92.

14. Fuchs D, Heinold A, Opelz G, Daniel V, Naujokat C. Salinomycin induces apoptosis and overcomes apoptosis resistance in human cancer cells. Biochem Biophys Res Commun 2009; 390: 743-749.

15. Kim KY, Yu SN, Lee SY, Chun SS, Choi YL, Park YM et al. Salinomycin-induced apoptosis of human prostate cancer cells due to accumulated reactive oxygen species and mitochondrial membrane depolarization. Biochem Biophys Res Commun 2011; 413: 80-86. 
16. Ketola K, Hilvo M, Hyotylainen T, Vuoristo A, Ruskeepaa AL, Oresic M et al. Salinomycin inhibits prostate cancer growth and migration via induction of oxidative stress. $\mathrm{Br} \mathrm{J} C a n c e r$ 2012; 106: 99-106.

17. Kim JH, Chae M, Kim WK, Kim YJ, Kang HS, Kim HS et al. Salinomycin sensitizes cancer cells to the effects of doxorubicin and etoposide treatment by increasing DNA damage and reducing p21 protein. Br J Pharmacol 2011; 162: 773-784.

18. Kim WK, Kim JH, Yoon K, Kim S, Ro J, Kang HS et al. Salinomycin, a p-glycoprotein inhibitor, sensitizes radiation-treated cancer cells by increasing DNA damage and inducing G2 arrest. Invest New Drugs 2012; 30: 1311-1318.

19. Lu D, Choi MY, Yu J, Castro JE, Kipps TJ, Carson DA. Salinomycin inhibits Wnt signaling and selectively induces apoptosis in chronic lymphocytic leukemia cells. Proc Natl Acad Sci USA 2011; 108: 13253-13257.

20. Sherr CJ, Roberts JM. CDK inhibitors: positive and negative regulators of G1-phase progression. Genes Dev 1999; 13: 1501-1512.

21. Deshpande A, Sicinski P, Hinds PW. Cyclins and cdks in development and cancer: a perspective. Oncogene 2005; 24: 2909-2915.

22. Nakayama KI, Nakayama K. Regulation of the cell cycle by SCF-type ubiquitin ligases. Semin Cell Dev Biol 2005; 16: 323-333.

23. Massague J. G1 cell-cycle control and cancer. Nature 2004; 432: 298-306.

24. Malumbres M, Barbacid M. Cell cycle, CDKs and cancer: a changing paradigm. Nat Rev Cancer 2009; 9: 153-166.

25. Musgrove EA, Caldon CE, Barraclough J, Stone A, Sutherland RL. Cyclin D as a therapeutic target in cancer. Nat Rev Cancer 2011; 11: 558-572.

26. Tsihlias J, Kapusta L, Slingerland J. The prognostic significance of altered cyclin-dependent kinase inhibitors in human cancer. Annu Rev Med 1999. 50: 401-423.

27. Gstaiger M, Jordan R, Lim M, Catzavelos C, Mestan J, Slingerland J et al. Skp2 is oncogenic and overexpressed in human cancers. Proc Natl Acad Sci USA 2001; 98: 5043-5048.

28. Reed SI. Deathproof: new insights on the role of skp2 in tumorigenesis. Cancer Cell 2008; 13: 88-89.

29. Frescas D, Pagano M. Deregulated proteolysis by the F-box proteins SKP2 and beta-TrCP: tipping the scales of cancer. Nat Rev Cancer 2008; 8: 438-449.

30. Yang G, Ayala G, De Marzo A, Tian W, Frolov A, Wheeler TM et al. Elevated Skp2 protein expression in human prostate cancer: association with loss of the cyclin-dependent kinase inhibitor p27 and PTEN and with reduced recurrence-free survival. Clin Cancer Res 2002 8: 3419-3426.

31. Traub F, Mengel M, Luck HJ, Kreipe HH, von Wasielewski R. Prognostic impact of Skp2 and p27 in human breast cancer. Breast Cancer Res Treat 2006; 99: 185-191.

32. Li JQ, Wu F, Masaki T, Kubo A, Fujita J, Dixon DA et al. Correlation of Skp2 with carcinogenesis, invasion, metastasis, and prognosis in colorectal tumors. Int J Oncol 2004 25: 87-95.

33. Bashir T, Dorrello NV, Amador V, Guardavaccaro D, Pagano M. Control of the SCF(Skp2-Cks1) ubiquitin ligase by the APC/C(Cdh1) ubiquitin ligase. Nature 2004; 428: 190-193.

34. Schuler S, Diersch S, Hamacher R, Schmid RM, Saur D, Schneider G. SKP2 confers resistance of pancreatic cancer cells towards TRAIL-induced apoptosis. Int J Oncol 2011 38: 219-225.

35. Wang XC, Tian LL, Tian J, Jiang XY. Overexpression of SKP2 promotes the radiation resistance of esophageal squamous cell carcinoma. Radiat Res 2012; 177: 52-58.

36. Totary-Jain H, Sanoudou D, Dautriche CN, Schneller H, Zambrana L, Marks AR Rapamycin resistance is linked to defective regulation of Skp2. Cancer Res 2012; 72 : 1836-1843.

37. Liscovitch M, Ravid D. A case study in misidentification of cancer cell lines: MCF-7/AdrR cells (re-designated NCI/ADR-RES) are derived from OVCAR-8 human ovarian carcinoma cells. Cancer Lett 2007; 245: 350-352.

38. Ozben T. Mechanisms and strategies to overcome multiple drug resistance in cancer FEBS Lett 2006; 580: 2903-2909.
39. Chen $\mathrm{H}, \mathrm{Ye} \mathrm{D}$, Xie X, Chen B, Lu W. VEGF, VEGFRs expressions and activated STATs in ovarian epithelial carcinoma. Gynecol Oncol 2004; 94: 630-635.

40. Huang M, Page C, Reynolds RK, Lin J. Constitutive activation of stat 3 oncogene product in human ovarian carcinoma cells. Gynecol Oncol 2000; 79: 67-73.

41. Huang $\mathrm{H}$, Zhao W, Yang D. Stat3 induces oncogenic Skp2 expression in human cervical carcinoma cells. Biochem Biophys Res Commun 2012; 418: 186-190.

42. Darnell JE Jr. STATs and gene regulation. Science 1997; 277: 1630-1635.

43. Cen B, Mahajan S, Zemskova M, Beharry Z, Lin YW, Cramer SD et al. Regulation of Skp2 levels by the Pim-1 protein kinase. J Biol Chem 2010; 285: 29128-29137.

44. Gao D, Inuzuka H, Tseng A, Chin RY, Toker A, Wei W. Phosphorylation by Akt1 promotes cytoplasmic localization of Skp2 and impairs APCCdh1-mediated Skp2 destruction. Nat Cell Biol 2009; 11: 397-408.

45. Rodier G, Coulombe P, Tanguay PL, Boutonnet C, Meloche S. Phosphorylation of Skp2 regulated by $\mathrm{CDK} 2$ and $\mathrm{Cdc} 14 \mathrm{~B}$ protects it from degradation by $\mathrm{APC}(\mathrm{Cdh} 1)$ in $\mathrm{G} 1$ phase. EMBO J 2008; 27: 679-691.

46. Roe JS, Kim HR, Hwang IY, Cho EJ, Youn HD. von Hippel-Lindau protein promotes Skp2 destabilization on DNA damage. Oncogene 2011; 30: 3127-3138.

47. Masuda M, Suzui M, Yasumatu R, Nakashima T, Kuratomi Y, Azuma K et al. Constitutive activation of signal transducers and activators of transcription 3 correlates with cyclin D1 overexpression and may provide a novel prognostic marker in head and neck squamous cell carcinoma. Cancer Res 2002; 62: 3351-3355

48. Bromberg JF, Wrzeszczynska MH, Devgan G, Zhao Y, Pestell RG, Albanese C et al. Stat3 as an oncogene. Cell 1999; 98: 295-303

49. Fukada T, Ohtani T, Yoshida Y, Shirogane T, Nishida K, Nakajima K et al. STAT3 orchestrates contradictory signals in cytokine-induced $\mathrm{G} 1$ to $S$ cell-cycle transition. EMBO J 1998; 17: 6670-6677.

50. Sherry MM, Reeves A, Wu JK, Cochran BH. STAT3 is required for proliferation and maintenance of multipotency in glioblastoma stem cells. Stem Cells 2009; 27: 2383-2392.

51. Jeselsohn R, Brown NE, Arendt L, Klebba I, Hu MG, Kuperwasser C et al. Cyclin D1 kinase activity is required for the self-renewal of mammary stem and progenitor cells that are targets of MMTV-ErbB2 tumorigenesis. Cancer Cell 2010; 17: 65-76.

52. Wander SA, Zhao D, Slingerland JM. p27: a barometer of signaling deregulation and potential predictor of response to targeted therapies. Clin Cancer Res 2011; 17: 12-18.

53. Zhang H, Kobayashi R, Galaktionov K, Beach D. p19Skp1 and p45Skp2 are essential elements of the cyclin A-CDK2 S phase kinase. Cell 1995; 82: 915-925.

54. Wang Z, Fukushima $\mathrm{H}$, Inuzuka $\mathrm{H}$, Wan L, Liu $\mathrm{P}$, Gao D et al. Skp2 is a promising therapeutic target in breast cancer. Front Oncol 2012.

55. Wang Z, Gao D, Fukushima H, Inuzuka H, Liu P, Wan L et al. Skp2: a novel potential therapeutic target for prostate cancer. Biochim Biophys Acta 2012; 1825: 11-17.

56. Xu HM, Liang Y, Chen Q, Wu QN, Guo YM, Shen GP et al. Correlation of Skp2 overexpression to prognosis of patients with nasopharyngeal carcinoma from South China. Chin J Cancer 2011; 30: 204-212.

57. Wen Z, Zhong Z, Darnell JE Jr. Maximal activation of transcription by Stat1 and Stat3 requires both tyrosine and serine phosphorylation. Cell 1995; 82: 241-250.

(c) (i)(2)(2) Cell Death and Disease is an open-access journa published by Nature Publishing Group. This work is licensed under a Creative Commons Attribution-NonCommercialShareAlike 3.0 Unported License. To view a copy of this license, visit http://creativecommons.org/licenses/by-nc-sa/3.0/

\section{Supplementary Information accompanies this paper on Cell Death and Disease website (http://www.nature.com/cddis)}

